\title{
Human - Wildlife Interaction: Wildlife Crop Raiding Conflict in Ethiopia
}

\author{
Haylegebriel Tesfay \\ Department of Biology (Zoological Science), Adigrat University, Ethiopia
}

\begin{abstract}
Conservation of wildlife requires an integrated effort from both conservation stewards and support from local communities. In Ethiopia Crop raiding is an increasing problem for communities living along with wildlife such as protected areas, sanctuaries and forest areas. The increases losses of crop by wildife cause loss of support for conservation by local communities and harm both wildlife and communities. Crop loss due to wildlife suffers farmers as they fail to support their families. Although local formers uses variety of mitigating methods to reduce crop loss caused by wildlife for years they remain less effective to reduce damage incurred by these wild animals. The objective of this work is through undertaking a systematic review on extent of crop raiding conflicts in Ethiopia, traditional methods used to mitigate/ prevent crop damage by wildlife by local communities and the extent of crop loss and its negative impact both on wildlife's and local communities to bring the information into one understanding. This information is important to farmers of rural communities and governmental agencies to implement conservation measures of wildlife animal's and improving the livelihoods of rural communities' lives alongside with wild animals.
\end{abstract}

Keywords: crop, raiding, wildlife, conflict, human

\section{Introduction}

Food security in Ethiopia is precarious, relying intimately on the results of a single cropping season. Crop farming provides as means of achieving food security for humans and crop residues as means feed source for livestock. However, production of agricultural crops is affected both by drought and severe loss of crops due to wild vertebrate animals (Dixon, 2005). The impact of crop damage inflicts by wildlife creates a negative attitude on the community towards wildlife and undermine effort of support for conservation.

Crop raiding by wildlife is increasing problem around protected areas and forest area (Adem, 2009). Destruction of forests, occupation original habitat of wildlife for purpose of investments increases the conflict of human-wildlife (Yihune, 2006; Mokenen et al., 2012). Due to the availability of food resources in agricultural crop fields wildlife population is increasing outside of protected areas and their crop raiding activities is affecting life of poor rural farmers and (Asmamaw and Verma, 2013). The objective of this work is through undertaking a systematic review on crop raiding conflict in Ethiopia to bring the information into one understanding. This information is important to farmers of rural communities and governmental agencies to implement conservation measures of wildlife animal's and improving the livelihoods of rural communities' lives alongside with wildlife.

\section{Materials and methods}

The review work carried out by understanding a systematic review on published and unpublished research papers related to human wildlife conflicts particularly on crop raiding. Only published research reports, postgraduate thesis works and $\mathrm{PhD}$ dissertation were included in presenting the review. Accordingly more than 41 research articles and postgraduate thesis works were reviewed and their major findings were extracted and presented in the paper.

\section{Results}

Wildlife involved in crop raiding and level of damage in Ethiopia

Wildlife ranging from invertebrate insect pests to vertebrate such as small mammals, birds and large mammal are reported to raid agricultural crops in Ethiopia (Quirin, 2005). Recent study in Bale Mountain National Park reported warthog and mountain nyala raid agricultural crops such as barley (Hordeum spp), linseed (Linum usitatissimum), vegetables including; potato(Solanum tuberosum), cabbages ( Asmamaw and Verma, 2013).

Similarly Yihune et al., (2005) reported an average crop loss per households of $117+10 \mathrm{~kg}$ due babbons. Hamadryads baboon lives proximal to agricultural areas raid crops and hence, considered as crop pests (IUCN, 1996). The settlement of habitat of baboons by humans for sugarcane plantation associated with crop production in small scale farming increases the conflict with baboons as they raid cultivated crops (Admasu et al., 2014). This crop raiding conflict by wildlife in protected area jeopardizes the park community relations (Admasu et al., 2014).

In Ethiopia elephants reported as crop raiders and given more attention (Kumssa and Bekele, 2013). Cultivated crops are attractive to elephants as alternative source of foods creating conflict with communities living adjacent to protected areas (Yirmed, 2008). In Churchura- National Park crops such as: Zea mays L and Sorghum bicolor faced problem of raiding by elephants (Meseret, 2006; Belayneh and Demissew, 2011). In Ethiopia elephants raid agricultural crops such as; vegetables, fruits and crop stores around house ranges and individual farmers suffer from damage by elephants risk their lives in defense of their crops (Reddy and Workneh, 2014). In the Babile elephant sanctuary, raiding of crops such: sorghum, maize, mango, papaya, pumpkin, sweet potato and ground nut by elephants reported ( Biru and Bekele 2012). Admasu (2006) reported that the main elephant group taking part in crop-raiding are the bulls 


\section{International Journal of Science and Research (IJSR) \\ ISSN (Online): 2319-7064 \\ Index Copernicus Value (2013): 6.14 | Impact Factor (2015): 6.391}

group having 3 to 6 members, sometimes followed by cows and calves group having 5 to 8 elephants.

Interview with respondents in Kafta-Sheraro National Park reported Elephants cause social problems; prevent people from walking at night, killing peoples, brought tsetse flies which causes trypanosome in livestock and also causes extra labor cost on family members ( Mamo et al., 2013). Admasu (2006), reported settlement of peoples associated with distribution and movement patterns of elephants.

Warthog, Swayne's hartebeest, velvet monkey and Porcupine was reported as the most severe crop pests in Swayne's hartebeest sanctuary (Kumssa, 2006). Warthog causes severe damage due to its feeding and trampling to staple food grain maize(Zea mays) and non-grain food crop potato(Solanum tuberosum) that are planted for subsistence ( Kumssa and Bekele, 2013). Respondents claims wildlife induced damage to crop was more widespread and small damage on their crops caused by the wild animals is threatening their lives. Cultivated crops such as maize (Zea mays) and potato (Solanum tuberosum) and haricot beans are major crops raided by wildlife in Swayne's hartebeest sanctuary (Tekle, 1996). Kumssa and Bekele (2013) reported, most crop damage $(97.7 \%$ ) occurred within $0-2 \mathrm{~km}$ radius from the Sanctuary and only $2.3 \%$ damage was reported from more than $2 \mathrm{~km}$ away.

Crop raiding by wild animals cause food insecurity and loss of income to forest adjacent communities (Quirin, 2005). In Ethiopia wildlife such as bush pigs, baboons, giant forest hogs, warthogs, common monkey, and porcupine mentioned agricultural pests in villages close to forest areas (Gemechu et al., 2014). In Guassa community conservation area gelada baboons, klipspringers, duikers and rabbits raid crops such as barley, lentil, bean, wheat and peas mainly at the time of seedling (Engedasew, 2010). Subsistence farmers living to adjacent Denkroro forest ranked gelada baboons the most crop raiders on farmlands causing huge damage in farmlands throughout day. Direct field observation Adem (2009), reported bushbuck, duiker, and klipspringer actively destroy crops for a few weeks only after germination).

In Wonji-Shoa sugarcane plantation grivet monkey (Cercopithecus aethiops), hippopotamus (Hippopotamus amphibus) and warthog (Phacochoerus africanus) were reported to cause greater damage to sugarcane plantation. Admasu(2007), reported that warthogs causing damage on sugar cane plants by feeding on its roots, rhizomes and bases of its stalk which is supposed to give more yields per unit area. Admasu (2007) observed in field that grivet monkey chewing sugarcane plants like humans and cut matures sugarcane at center of the nodes and Hippopotamus repeatedly damage sugarcane plants at the shoots and younger parts of the plants.

In Ethiopia small mammals like rodent species are known as crop raiders for a long of time (Kumssa and Bekele, 2013). Approximately out of 84 species of rodents recorded $11 \%$, of them are major agricultural pests (Bekele and Leirs, 1997). Arvicanthis and Mastomys species are the major pests in Ethiopia (Bekele et al., 1993). Maize, enset and potatoes are the crops most affected by rodents (Tristiani et al., 2000; Makundi et al., 2005). A loss estimation of yield $26.4 \%$ and $94.4 \%$ in maize and cereal crops was reported in central and northern highlands of Ethiopia (Bekele et al. 2003; Meheretu et al., 2010).

\section{Community Measures for Deterring Crop Raiders}

The destruction of agricultural crops by wildlife has been a major problem that farmers near protected areas faced. These raids inflict heavy losses on farm produce with the cost borne by the local farmers. For example estimation in Tigray highland the loss of crop caused by rodents could have supported a family of five heads for about three months and the average loss in fields could have supported a family of the same size for about 2.4 months (Meheretu et al., 2014). Quirin (2005), reported loss crop in the absence of any protecting by wildlife is $100 \%$. Gardening crop flied during harvesting is most effective methods of preventing crop damage. Crop cultivators in western zone of Ethiopia reported in-field guarding was the primary effective means of preventing crop raiding by wild vertebrate pests and all the other strategies were described to be supplementary and minimally effective(Courtney, 2008)

The labor demand to mitigate crop raiding by wildlife is significant, all grown-up family member engaged in continuous protection (day and night) of crops from the first day of sowing until they put the harvest into granaries (Gemechu et al., 2014). However, gardening is not effective for some crop raiding species. Quirin (2005), reported that guarding is not effective method against baboons species as they not afraid to children's and women's and continue raid of crops in their presence. Gardening also causes social destruction which separated families as males involves in gardening at night in field crops and limit school students to go school as they involve in deterring crop raiders species (Griffiths and Southey, 1995)

In Ethiopia many farmers rely on self- defense against crop damage by/wildlife. For example, around the Babile elephant sanctuary, farmers use traditional crop protection methods such as staying in field watching, throwing objects, producing noise by beating drums or shouting loudly and dig wide and deep trench as means of barriers for elephants crop raiding and the methods are successful ( Reddy and Workneh, 2014).

Fencing is other protection methods employed by farmers in Ethiopia. For example farmers in use live fence using tree species of along the boundary of anal crops to protect crops, mainly from domestic animals (Gemechu et al., 2014). However, farmers consistently reported that live fences were ineffective as protection against many wild mammal crop pests such as baboons, monkeys, and giant forest hogs, but agreed that strong (matured), tight, and maintained live fences could keep bush pigs and porcupines away from crops. Apart from fencing crops other mitigating strategies such as migrating to areas with potential for forest clearing to distance crop fields from forests, allowing immigrants to settle along forest edges and removing trees from annual crop fields to reduce the opportunities for 


\section{International Journal of Science and Research (IJSR) \\ ISSN (Online): 2319-7064}

Index Copernicus Value (2013): 6.14 | Impact Factor (2015): 6.391

monkeys to find shelter in crop fields were repeatedly reported by farmers in interviews.

\section{Conclusion}

Crop raiding by wildlife has a significant impact on rural people's livelihoods and lives. The conflict occurs between humans and wildlife animals is threatening for the life rural communities and large number of wildlife species. Research findings shows that although large number of farmers suffers crop raiding by wildlife most affected communities not reported the problem any concerned bodies. This leads to hidden the existing problem due to lack communication among the suffered communities and responsive governmental bodies. Due to lack of communication the strategies employed by farmers to mitigate against crop raiding is leading to disruption of the ecosystem service The inadequate response given by concerned governmental agencies to the existing problem wild life leads society to thin wildlife areas. To be effective, mitigation strategies must take into account not only the degree to which wildlife conflicts impact crop yields and household economics but also research works must focus how and why people perceive crop losses the way they do, (2) what they expect from any intervention, and (3) who they expect to take responsibility for the issue.

\section{References}

[1] Ademasu M. (2006). History and status of the population of African elephant (Loxodonta africana Blumenbach, 1797) and human elephant conflict in chebera churchura national park. MSc thesis, Addis Ababa University. Pp. 1-99

[2] Admassu M. (2007). Damage caused by large mammals in Wonji-Shoa Sugarcane Plantation, Central Ethiopia. MSc thesis, Addis Ababa University. Pp. 1-76

[3] Admassu M. Mamo Y. and Bekele. A (2014). Abundance of hamadryas baboon and conflict with humans in Awash National Park, Ethiopia. International Journal of Biodiversity and Conservation. Vol. 6(3), pp. 200-209

[4] Adem M. (2009). Population Status of Gelada Baboon and Human - Wildlife Conflict In and Around Denkoro Forest, Ethiopia. MSc thesis, Addis Ababa University. Pp. 1-95

[5] Asmamaw D. and Verma A. (2013).Ecotourism for environmental conservation and community livelihoods, the case of the Bale Mountain National Park, Ethiopia. Journal of Environmental Science and Water Resources. Vol. 2(8) :250 - 259

[6] Bekele A. Capanna E. Corti M. Marcus F. and Schlitter A. (1993). Systematic and geographic variation of Ethiopian Arvicanthis (Rodentia, Muridae). Journal of Zoology. 230: 117-134.

[7] Bekele A. and Leirs H. (1997). Population ecology of rodents of maize fields and grassland in central Ethiopia. Belgian Journal of Zoology, 127, 39-48

[8] Bekele A. Leirs H. Verhagen R. (2003). Composition of rodents and damage estimates on maize farms at Ziway, Ethiopia. Australian Centre for International Agricultural Research, pp. 262- 263.
[9] Belayneh A. and Demissew S. (2011). Diversity and Population Structure of Woody Species Browsed by Elephants in Babile Elephant Sanctuary, eastern Ethiopia: an implication for conservation. Ee-JRIF 3(1):pp 20-32

[10]Biru Y. \& Bekele A. (2012). Food habits of African elephant (Loxodonta africana) in Babile Elephant Sanctuary, Ethiopia Tropical Ecology 53(1): 43-52

[11] Engdasew(2010). Human - wildlife conflict involving E thiopian Wolf and Gelada baboon in and aroud Guassa community comservation area, North Shoa, Ethiopia, MSc thesis, Addis Ababa University .pp 1-100

[12] Gemechu T. Lowe A. Senbeta F. And Hylander K. (2014). Balancing Ecosystem Services and Disservices: Smallholders Farmers' Use and Management of Forest and Trees in an Agricultural Landscape in Southwestern Ethiopia. Ecology and Society 19(1): 36279-190130

[13] Griffiths M. and Southey C. (1995). The opportunity costs of biodiversity conservation in Kenya. Ecological Economics. 12: 125-139

[14] IUCN (1996). IUCN Red List of Threatened Animals. IUCN, Switzerland, Gland.

[15] Kumssa T. (2006). Human-Wildlife Conflict and Population Status of Swayne's Hartebeest in Senkele Swayne's Hartebeest Sanctuary. MSc thesis. Pp. 1-114

[16] Kumssa T. and Bekele A. (2013). Human-Wildlife Conflict in Senkele Swayne's Hartebeest Sanctuary, Ethiopia. Journal of Experimental Biology and Agricultural Sciences. 1(1): 32-38

[17] Mamo M. Bouer H. and Tesfay Y. (2013). Crop Damage By African Elephants Assessment In Kafta Sheraro National Park, Ethiopia

[18] Makundi R. Bekele A. Leirs H. Massawe A. Rwamugira W. Mulungu S. (2005a). Farmer's perceptions of rodents as pests: knowledge, attitudes and practices in rodent pest management in Tanzania and Ethiopia. Belg. J. Zool. 135: 153-157

[19] Meheretu Y. Kiros W. Deckers S. Raes D. Makundi R. Leirs H. (2010) . Farmers'perspectives of rodent damage and management from the highlands of Tigray,Northern Ethiopia. Crop Prot. 29 (6): 532- 539

[20] Meheretu Y. Sluydts V. Kiros W. Bauer H . Mekonen A. Gidey Y. Mulungu L. Mitiku H( 2014). Rodent abundance, stone bund dens ity and its effec ts on crop damage in the Tigray highlands, Ethiopia. Crop Protection 55: 61- 67

[21] Mekonnen, A Bekele A Peter J. Atickem A. and Stenseth N.( 2012). Newly Discovered Bale Monkey Populations in Forest Fragments in Southern Ethiopia: Evidence of Crop Raiding, Hybridization with Grivets, and Other Conservation Threats. American Journal of Primatology. Pp 1-10

[22] Quirin C. (2005). Crop Raiding by Wild Vertebrates in the Illubabor Zone, Ethiopia. Report Submitted In Partial Fulfillment of The Post-Graduate Diploma in Wildlife Management. Pp 1-52

[23] Quirin C.(2008) . A Recipe for Conflict: Food Security, Politics and Perceptions of Wildlife Damage in Western Ethiopia. A Thesis Submitted For The Degree Of Masters Of Science In Wildlife Management At The University Of Otago, Dunedin New Zealand

[24] Reddy U. and Workneh S. (2014). Conflict between the conservation of elephant and human activities: In case 


\section{International Journal of Science and Research (IJSR) \\ ISSN (Online): 2319-7064}

Index Copernicus Value (2013): 6.14 | Impact Factor (2015): 6.391

of Babile Elephant sanctuary. Journal of Geography and Regional Planning. 7( 2): 25-29

[25] Tekle F. (1996).Community-based conservation of Senkele Swayne's Hartebeest Sanctuary. MSc Thesis, University College of Wales, Canterbury, pp: 32-39

[26] Tristiani H. Makundi O. Kuno E. (2000). Rice plantdamage distribution and home range distribution of the rice field rat Rattus argentiventer (Rodentia: Muridae). Belg. J. Zool. 130: 83-91

[27] Yihunie M. (2006). Human - wildlife (Ethiopian wolf and Gelada baboon) conflict in and around Simien Mountains National Park. MSc. Thesis), Addis Ababa University, Ethiopia 1-67

[28] Yirmed D. (2008). The ecology and conservation of the relice elephant population in horn Africa. Four year report. Addis ababa, Ethiopia

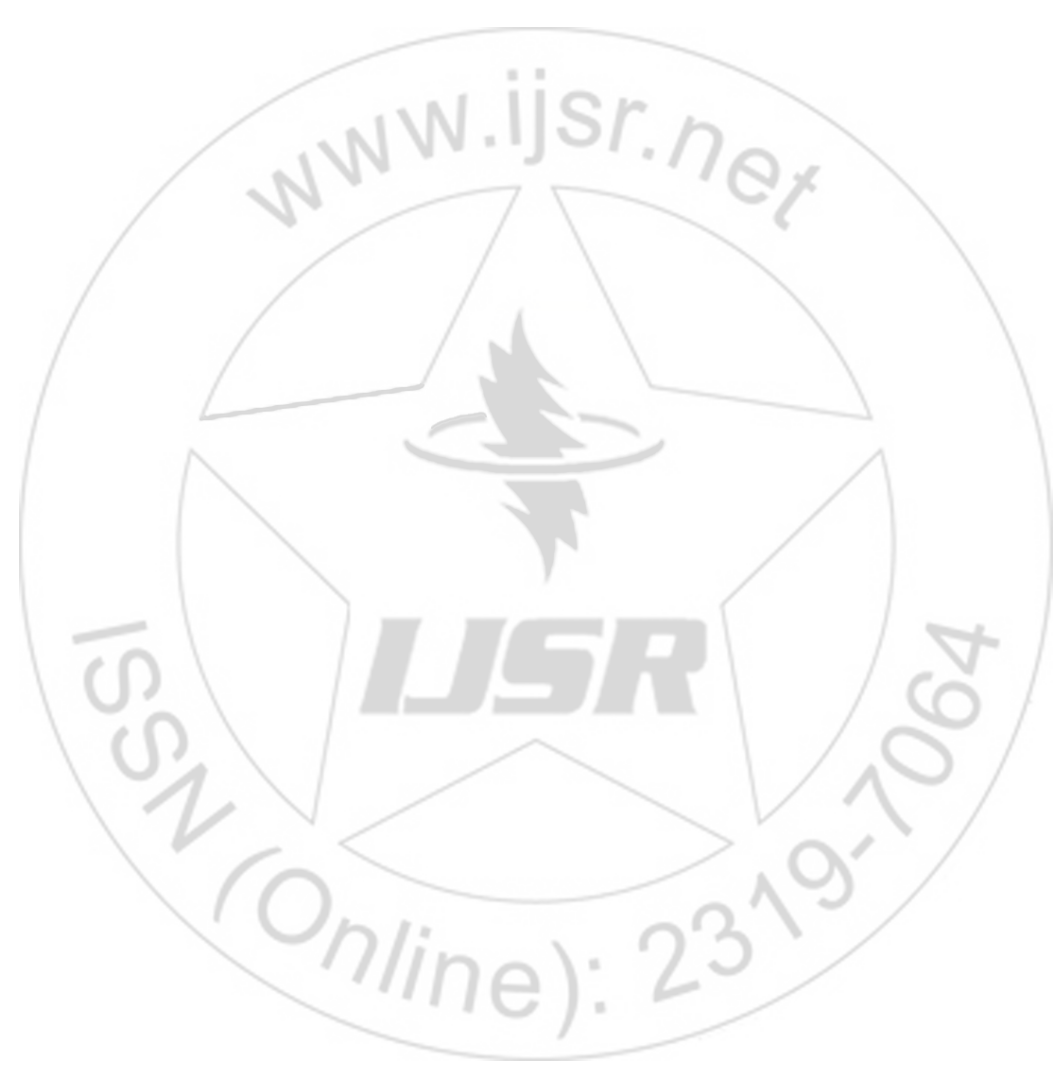

Volume 5 Issue 5, May 2016 